\title{
Trends in a recreational fishery for mussels in eastern South Africa, based on postal, telephone and online surveys
}

\author{
Erika Steyn $^{* a}$, Johan C. Groeneveld ${ }^{\text {a, b }}$, Jorge Santos ${ }^{c}$, Alke Kruger ${ }^{d}$, Xolani I. Mselegu ${ }^{\text {a }}$, Michael H. \\ Schleyer ${ }^{\text {a }}$ \\ ${ }^{a}$ Oceanographic Research Institute, 1 King Shaka Avenue, Point, Durban \\ ${ }^{b}$ School of Life Sciences, University of KwaZulu-Natal, Pietermaritzburg, KwaZulu-Natal, South Africa \\ ${ }^{c}$ Norwegian College of Fishery Science, University of Troms $\varnothing$, Norway \\ d South African Association for Marine Biological Research, 1 King Shaka Avenue, Point, Durban \\ *Corresponding author. \\ E-mail address: erika@ori.org.za (E. Steyn)
}

https://doi.org/10.1016/j.ocecoaman.2019.104863

\begin{abstract}
The intertidal brown mussel Perna perna is targeted by recreational and subsistence fisheries in KwaZulu-Natal, South Africa. The recreational mussel fishery is monitored by off-site postal, telephone and online questionnaire surveys, assessed in this study. Trends in fisher avidity (proportion of permit holders that went fishing), mean number of outings undertaken per quarter year and catch per unit effort (CPUE, as numbers of mussels collected per outing) between 2002 and 2015 were investigated, based on survey responses and available permit sales data. Fisher avidity was greater during summer, for fishers $<30$ y old, and for residents of coastal districts. Spring low tide windows limited the number of outings to an average of 3-4 per quarter, during which most fishers collected close to the allowed daily bag limit of 30 mussels. The CPUE trend was constrained by the bag limit, and censored regression models were unable to trace the relative abundance of mussels at the spatio-temporal scale investigated. Despite low response rates and changes in survey strategy, trends based on off-site survey data were broadly consistent, providing the only long-term record of the fishery. Survey response rates, costs and logistical constraints were compared, to develop an optimal survey strategy. We suggest a mixed-mode strategy, increased use of online resources, greater representativity, improved outreach and feed-back of survey results. On-site information is required to verify data from off-site surveys.
\end{abstract}

Keywords: Perna perna, recreational fishery, fishery monitoring, questionnaire surveys, survey bias, catch statistics, fisher avidity 


\section{Introduction}

The brown mussel Perna perna (Linnaeus, 1758) is the dominant mussel species on shallow intertidal reefs in KwaZulu-Natal (KZN) province, eastern South Africa, where it occurs in dense mussel beds that are exploited by recreational and subsistence fishers (Jackson, 1976; Sink et al., 2005; Steyn, 2016). The subsistence fishery is mostly confined to the northern part of KZN (north of Richards Bay and within the Isimangaliso Wetland Park; Figure 1) and the KZN south coast where local fishers are allowed to harvest several species of shellfish in the intertidal (Harris et al., 2007; Tomalin and Kyle, 1998; WIOFish, 2013). The recreational fishery is widespread along the KZN coast and removes much larger quantities of mussels annually (Steyn, 2016). This study focussed on the recreational fishery, for which long-term data from off-site surveys were available.

Recreational fishers collect mussels mainly during day-time spring low tides over weekends and holidays, restricting them to a single outing per day. Mussels are used for seafood or bait for angling. Fishers require recreational fishing permits, obtained for a nominal fee at post offices. Permits prohibit the commercial sale of mussels, restrict individual holders to 30 mussels per day, and prescribe the use of a narrow blade for removing mussels from reef beds. Of 13 000-15000 recreational fishing permits for invertebrates (including spiny lobsters, oysters, crabs and prawns) sold per year between 2010 and 2014, those for mussels made up 23-28\% (Steyn, 2016; Steyn and Schleyer, 2014).

Anecdotal reports indicate that mussel stocks in eastern South Africa were far greater in the early 1900 s than at present (pers. comm. MHS). Surveys by Jackson (1976) in the 1970s showed that harvesting had reduced stocks, allowing competitive zoanthids to establish stable communities within mussel beds. Rius et al. (2006) found no significant correlations between indicators of human exploitation and condition of mussel stocks along the south coast of South Africa, which is less heavily exploited than the east coast. In KZN, high levels of mussel harvesting have greatly reduced mussel stocks at several monitored sites, with moderate recovery measured where collecting was subsequently prohibited (Steyn and Schleyer, 2012).

Information on total catch and fishing effort over time are important for stock status assessments, and for measuring spatio-temporal trends in the numbers of fishers, or fishing pressure. Attempts to obtain representative data from recreational mussel fishers along the KZN coast have met with varying success. At first, a permit requirement to submit annual catch returns to licensing authorities was not enforced, resulting in poor coverage of the fishery between 1974 and 1998 (Tomalin, 1993; Tomalin and Kruger, 2000; Robertson, 2003). Likewise, coastal creel patrols by the Ezemvelo KwaZulu-Natal Wildlife (EKZNW) conservation body between 1995 and 2015 could not provide realistic estimates of recreational fishing effort and mussel offtake, mainly because patrols focused on enforcement of fishery regulations, and not on monitoring. To improve data availability, off-site surveys based on postal and telephone questionnaires were initiated in the fishery during the late 1990s, supplemented by online questionnaires after 2011 (Kruger and Schleyer, 2003; Kruger and Tomalin, 1996; Steyn and Schleyer, 2014).

Off-site surveys are more cost-effective than creel patrols but are subject to specific limitations and biases (Harris and Bergerson, 1985; Pollock et al., 1994; Tarrant et al., 1993). For example, data obtained from self-administered questionnaires may be affected by declining response rates, with non-respondent groups differing systematically from those that responded to surveys (De Leeuw 
and De Heer, 2002; Groves, 2006; Wallen et al., 2016). Follow-up surveys are then required to correct for non-respondents (Barrett et al., 2017; Connelly et al., 2000; McClanahan and Hansen, 2005; Tarrant et al., 1993; Van der Hammen et al., 2016). Mixed-mode designs that use a combination of survey types improve response rates (De Leeuw, 2005), but may introduce mode bias by sampling demographically different groups (Lesser et al., 2016; Wallen et al., 2016; Zarauz et al., 2015). Recall bias, or the inability of respondents to accurately recall fishing activities in the past, can also affect questionnaire data (Pollock et al., 1994; Tarrant et al., 1993). Nevertheless, where bias of off-site surveys can be reduced through design and implementation, they can produce fishing effort and catch estimates similar to those from on-site monitoring (Hartnill and Edwards, 2015).

We analysed data of permit sales, and of responses to postal (2002-2015), telephone (2002-2010) and online (2011-2015) questionnaire surveys of recreational mussel fishers in KZN to investigate trends in fisher avidity (proportion of permit holders that went fishing), fishing effort (number of outings made to collect mussels) and catch per unit effort (CPUE; number of mussels collected per outing). In addition to survey mode, the effects of year, season, fishing area, respondent age group and residential origin on fisher behaviour (avidity and number of outings undertaken) and mussel CPUE were investigated. Response rates to surveys, relative cost and logistical constraints were compared, with the aim of improving the off-site survey strategy.

\section{Materials and methods}

\subsection{Sampling area}

The KZN coastline was subdivided into four fishing areas corresponding to historical fishery management zones (Pradervand and Govender, 2001; Figure 1). From north to south, they were: Elephant coast (mainly protected areas, including the Isimangaliso Wetland Park); Dolphin coast (residential areas and popular holiday towns); Central KZN (high-density urban area); and South Coast (mixture of residential areas, light industry and holiday resorts). Unknown locations or those outside KZN were assigned to 'Other fishing areas'.

The residence district of respondents was categorised according to municipalities (Figure 1). The eThekwini municipality (ETHEK) includes Durban city, with a high population density. The uMgungundlovu (UMGUN) municipality also has a high population density and is located close to the coast. The uGu (UGU), iLembe (ILEM) and King Cetshwayo (KING) municipalities are coastal districts with lower population densities than ETHEK and UMGUN. Residents from a major inland metropole (Gauteng, GAU) form the bulk of seasonal visitors to the KZN coast. Respondents from other inland municipalities or districts were grouped as 'Other respondents'. 


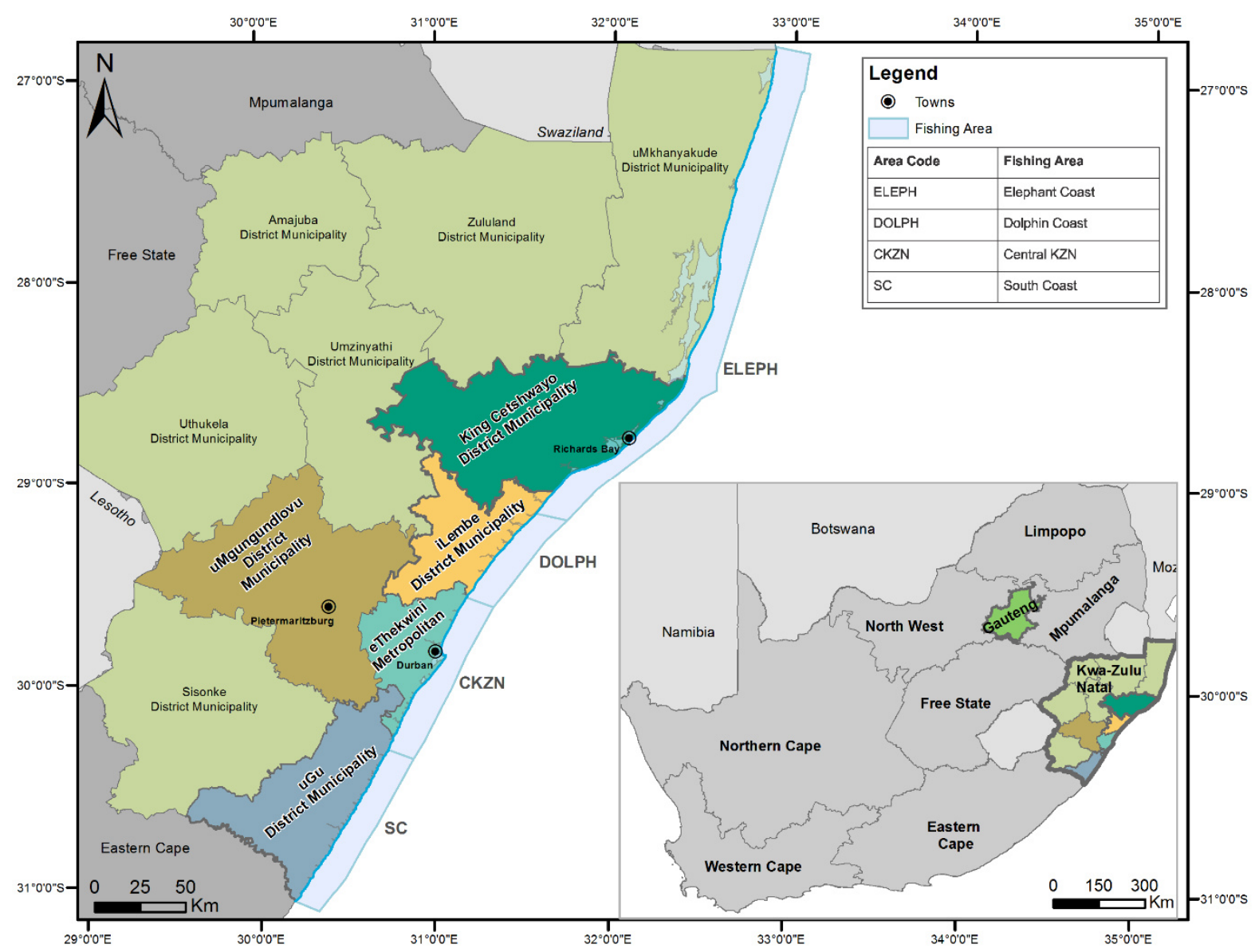

Figure 1. Map of KwaZulu-Natal, showing residence districts of mussel permit holders, and fishing areas were mussels were collected. The provinces of KwaZulu-Natal and Gauteng in South Africa are also shown.

\subsection{Surveys}

Off-site surveys of permit holders in the recreational fishery were conducted quarterly between 2002 and 2015, in January, April, July and October of each year, except in 2010. Individual questionnaires focused on collection activities during the preceding three-month period: the April survey therefore covered fishing activities between January and March (austral summer); the July survey covered April to June (autumn); the October survey covered July to September (winter) and the January survey October to December (spring). Respondents were asked to report 1) the total number of mussel outings undertaken, 2) the number of outings when no mussels were collected, and 3) the mean catch per outing, excluding nil catches (Appendix A; Questionnaire A.1). To eliminate potential ambiguity, the wording of questions (1) and (3) was adjusted in 2013 to, respectively: the number of outings during which mussel catches were harvested, and the total number of mussel collected during the three-month survey period (Appendix A; Questionnaire A.2). As mussels were generally collected on all outings, responses were expected to be consistent after the change in wording.

Postal surveys (2002-2010 and 2012-2015) relied on addresses supplied by individuals purchasing recreational marine invertebrate permits, and were obtained from licensing agencies every three months. Questionnaires were then posted to randomly-selected permit holders on the list. Postal 
surveys were affected by an administrative change-over in 2010, when recreational fisheries were moved from provincial to national jurisdiction, and the post office became the sole agent for permit sales. As a result, surveys for the first three quarters in 2010 could only be posted in October, extending the regular three-month recall period of respondents to up to ten months for permits bought in January. Postal questionnaires were designed to cover all recreational invertebrate fisheries; therefore not all postal recipients were mussel collectors. The postal response rate was adjusted for the number of undelivered questionnaires.

Telephone surveys (2002-2010) were used as a follow-up to non-respondents of postal surveys, and were conducted quarterly, four weeks after the respective postal surveys. Telephone surveys were conducted between $18 \mathrm{~h} 00$ and $20 \mathrm{~h} 30$ over a two-week period, with interviews based on the layout of the postal questionnaires. The jurisdictional change in 2010 likewise delayed telephone surveys during that year, to February 2011, extending the recall period to up to 13 months for permits bought in January the previous year. As with postal surveys, not all permit holders contacted by telephone held mussel permits. Telephone surveys were discontinued after February 2011.

Online surveys (2010-2015) relied on individual email addresses sourced from postal survey respondents. Permit holders were emailed a link to an online survey, or questionnaires were emailed to them, on request. The online survey was advertised through local online fishing and spearfishing forums, to obtain more email addresses and increase the sample size after 2011. Unlike postal and telephone surveys, the online surveys were not based on a complete list of permit holders, and the proportion of online questionnaires that reached individuals without valid mussel permits could not be determined. No response rate was therefore calculated for online surveys.

\subsection{Data treatment}

The survey data were cleaned by removing anomalous records in which the number of outings per quarter, or number of mussels collected per outing, was clearly incorrect or mismatched. Records reflecting no outings during a three-month survey period ( $47 \%$ of records) were excluded from analyses of number of outings and CPUE. Survey data from 2010 were also excluded from these analyses (3\%), because the longer recall periods in that year may have affected reporting accuracy. We assumed that fishers would be able to recall whether they had been on at least one outing over the 12-month recall period, and the 2010 data were thus included in the analysis of fisher avidity. The maximum number of outings was set at 20 per quarter, because mussel beds are only exposed during spring low tides when sea conditions are favourable, and recreational fishing takes place mainly over weekends and holidays. Only $39(0.8 \%)$ of 5067 records reported $>20$ outings per quarter and were excluded from further analysis. The maximum number of mussels collected per outing was set at 50, accounting for the present (30 mussels/day, since 1998) and past (50 mussels/day) bag limits. Few records $(<1 \%)$ exceeded 50 mussels and were excluded because we focussed on the legal recreational fishery. Furthermore, patrols by fishery compliance officers during the surveyed period found few instances when the mussel bag limit had been exceeded (Steyn, 2017; Tomalin and Kyle, 1998).

For the demographic analysis, respondent data were categorized into four age groups: $<30$ y (young), 30-59 y (middle-age), $\geq 60$ y (senior) and unknown age. Two time periods were considered: 2002-2010 (coinciding with the postal and telephone surveys) and 2011-2015 (postal and online surveys). 


\subsection{Data analysis}

Variability in fisher avidity, number of outings undertaken and mussel CPUE, as an index of relative abundance, was investigated using Generalized Linear Mixed Models (GLMMs) and Generalized Additive Mixed Models (GAMMs) in the statistical software package $R$, version 3.3.1 (R Core Team, 2016). The R-libraries 'Ime4' (Bates et al., 2015) and 'Imtest' (Zeileis and Hothorn, 2002) were used to perform GLMMs, with support functions for the models provided by the 'MASS' package (Venables and Ripley, 2002). The CPUE data that were right-censored at the daily bag limit were poorly modelled by GLMMs. Subsequently, the 'gamlss.tr' library (Stasinopoulos and Rigby, 2018) was used to define a right-censored data distribution, which could be used as input for the GAMMs performed by the 'gamlss' library (Rigby and Stasinopoulos, 2005).

Survey mode, season, residential district, respondent age, fishing area and question wording (before and after July 2013) were modelled as categorical factors (Table 1). Survey year was modelled as a continuous variable, but treated as a discrete variable in the figures to aid trend visualization. Respondent identity was added as a random effect in the models, because individual respondent behaviour may have influenced effort and catch data. Postal survey mode, survey year 2002, autumn, pre-2013 question wording, ETHEK residential district, middle-aged respondents and the Central KZN fishing area were used as model intercepts where applicable. The GLMMs were fitted by maximizing the log-likelihood using the Laplace Approximation. The Cole and Green algorithm (Cole and Green, 1992) was used to fit the penalized log-likelihood function of the GAMMs.

Table 1. Independent variables tested in fisher avidity, outings and CPUE models using the questionnaire survey data for the KZN mussel fishery.

\begin{tabular}{|c|c|c|c|}
\hline $\begin{array}{l}\text { Independent } \\
\text { variables }\end{array}$ & Type & Description & Notes \\
\hline $\begin{array}{l}\text { SM } \\
\text { (Survey mode) }\end{array}$ & Categorical & Postal, Telephone, Online & \\
\hline $\begin{array}{l}\mathbf{Y} \\
\text { (Survey year) }\end{array}$ & Continuous & $2002-2015$ & \\
\hline $\begin{array}{l}\text { SEAS } \\
\text { (Surveyed season) }\end{array}$ & Categorical & $\begin{array}{l}\text { Summer (Jan-Mar),Autumn (Apr-Jun), Winter (Jul-Sep), } \\
\text { Spring (Oct-Dec) }\end{array}$ & \\
\hline $\begin{array}{l}\text { QW } \\
\text { (Change in question } \\
\text { wording after Jan } \\
\text { 2013) }\end{array}$ & Categorical & Surveys up to Jan 2013, surveys after Jan 2013 & $\begin{array}{l}\text { Not used in } \\
\text { avidity models }\end{array}$ \\
\hline $\begin{array}{l}\text { RD (Respondent } \\
\text { residential district) }\end{array}$ & Categorical & ETHEK, GAU, ILEM, KING, UGU, UMGUN, OTHER & \\
\hline $\begin{array}{l}\text { AG (Respondent } \\
\text { age) }\end{array}$ & Categorical & $\begin{array}{l}\text { Young ( }<30 \text { years), Middle-age ( } 30-59 \text { years), Senior } \\
\text { ( } \geq 60 \text { years) }\end{array}$ & \\
\hline $\begin{array}{l}\text { FA } \\
\text { (Fishing area) }\end{array}$ & Categorical & Elephant coast, Dolphin coast, Central KZN, South coast & $\begin{array}{l}\text { Not used in } \\
\text { avidity models }\end{array}$ \\
\hline $\begin{array}{l}\text { ID } \\
\text { (Respondent ID) }\end{array}$ & Categorical & $\begin{array}{l}\text { Avidity models: } 4238 \text { fishers; Outings models: } 2644 \text { fishers; } \\
\text { CPUE models: } 2535 \text { fishers }\end{array}$ & \\
\hline
\end{tabular}


Final models were selected based on a stepwise approach, involving modelling combinations of error structure, link functions and explanatory variables. Models were compared using likelihood ratio tests, and those with the lowest Akaike's information criterion (AIC), and randomly distributed residuals on plots, were selected as the best-fitting final models.

GLMMs with a binomial error structure and a logit link function were selected to model fisher avidity, after coding the data as ' 0 ' for inactive (collector had a valid permit, but did not undertake an outing during the quarter) and ' 1 ' for avid (permit holder undertook an outing during the quarter) (Table 2).

GLMMs with a negative binomial error structure and a log-link function were selected to model the number of outings, which comprised over-dispersed count data.

The mean CPUE per respondent per quarter was obtained from

$$
\text { CPUE }=\frac{C}{T}
$$

where $\mathrm{T}$ is the number of mussel outings per quarter reported by a respondent, and $\mathrm{C}$ is the total number of mussels collected for all outings made during that quarter. GAMMs with a log-normal error structure right-censored at the current bag limit of 30 mussels/outing and the log-link function were selected to model the mean CPUE. 
Table 2. Coefficients ( \pm SE) of parameters retained in the final GLMMs and GAM that describe fisher avidity, number of outings and mussel CPUE. Estimates marked with * were significantly different ( $p$ $\leq 0.05$ ) from the intercept. The avidity model predicts the percentage of mussel permit holders using their permits. The number of observations ( $n$ ), analysis performed, error structure, link function and Akaike's information criterion (AIC) for the best-fitting model are shown.

\begin{tabular}{|c|c|c|c|}
\hline & Avidity & Outings & CPUE \\
\hline Factors & $\begin{array}{c}\mathrm{SM}+\mathrm{Y}+\mathrm{SEAS}+\mathrm{RD}+\mathrm{AG}+ \\
\text { random(ID) }\end{array}$ & $\begin{array}{l}\mathrm{Y}+\mathrm{RD}+\mathrm{QW}+\mathrm{FA}+ \\
\quad \text { random(ID) }\end{array}$ & Y \\
\hline Analysis & GLMM & GLMM & GAM \\
\hline Error & Binomial & Negative binomial & $\begin{array}{l}\text { Right-censored lognormal } 2 \\
(\mathrm{mu}=\text { median; } \mu=(0,+\infty))\end{array}$ \\
\hline Link & Logit & Log & Log \\
\hline AIC & 12791.74 & 21734.20 & 28521.44 \\
\hline $\mathrm{n}$ & 9805 & 5028 & 4777 \\
\hline \multirow[t]{2}{*}{ Notes } & $\begin{array}{l}\text { Data coded to ' } 0 \text { ' for inactive, } \\
\text { ' } 1 \text { ' for active }\end{array}$ & $\begin{array}{l}\text { Only data from avid fishers } \\
\text { included in analysis }\end{array}$ & $\begin{array}{c}\text { Only data from avid fishers } \\
\text { included in analysis and CPUE } \\
\text { right-censored at } 30 \text { mussels/ } \\
\text { outing }\end{array}$ \\
\hline & Estimate (SE) & Estimate (SE) & Estimate (SE) \\
\hline (Intercept) & $56.57(2.06)^{*}$ & $3.41(0.10)^{*}$ & $28.31(0.50)^{*}$ \\
\hline Mode: Online & +3.80 (2.58) & & \\
\hline Mode: Telephone & $-14.94(1.48)^{*}$ & & \\
\hline Year & $+0.50(0.20)^{*}$ & $-0.05(0.01)^{*}$ & $-0.03(0.0001)$ \\
\hline Season: Spring & $-5.68(1.72)^{*}$ & & \\
\hline Season: Summer & $+5.00(1.63)^{*}$ & & \\
\hline Season: Winter & $-9.45(1.69)^{*}$ & & \\
\hline$R D: G A U$ & $-26.03(2.67)^{*}$ & $+0.04(0.21)$ & \\
\hline$R D:$ ILEM & $+9.15(2.11)^{*}$ & $+0.83(0.17)^{\star}$ & \\
\hline RD: OTHER & $-18.19(3.80)^{*}$ & $-0.23(0.24)$ & \\
\hline$R D: U G U$ & $+7.24(2.44)^{\star}$ & $+0.59(0.17)^{*}$ & \\
\hline$R D: U M G U N$ & $-6.58(2.89)^{*}$ & $-0.27(0.16)$ & \\
\hline$R D: K I N G$ & $-7.18(4.65)$ & $-0.60(0.26)^{*}$ & \\
\hline Age: Young & $+5.37(2.56)^{\star}$ & & \\
\hline Age: Senior & $-0.08(1.56)$ & & \\
\hline Age : Unknown & $-16.51(7.65)^{*}$ & & \\
\hline Question Wording & & $+0.48(0.15)^{*}$ & \\
\hline FA: Dolphin coast & & $-0.27(0.09)^{*}$ & \\
\hline FA: Elephant coast & & $-0.02(0.24)$ & \\
\hline FA: Other & & $-0.16(0.15)$ & \\
\hline FA: South coast & & $+0.10(0.13)$ & \\
\hline
\end{tabular}

\subsection{Survey costs}

The cost per respondent was calculated by dividing the sum of labour and operational costs by the number of mussel permit holders sampled per survey between 2012 and 2014. Labour costs were made up of costs for survey design, data capture and validation, and for postal surveys, included verification of postal addresses. Operating costs included printing, postage and stationary for postal 
surveys. For telephone surveys, the cost per sample was calculated as the average number of calls made and their duration during the 2002-2009 period, multiplied by the ratio of landline to cell phone numbers obtained from 2010-2015 permit sales, at 2019 call rates. Labour costs of conducting telephone interviews were added. The only operating cost for the online survey was the annual subscription fee to the SurveyMonkey website. The mean number of online respondents between 2011 and 2015 was used to estimate survey costs. Hidden costs included administrative functions, and use of organizational inter- and intranet infrastructure.

\section{Results}

\subsection{Permit sales}

An average of $3723 \pm 845$ (SD) annual mussel permits and $197 \pm 194$ temporary permits (30-day validity) were sold between 2002 and 2015. Demographic data of permit holders were available on the post office database from 2010 onwards. The database contained 23300 records of individuals that bought mussel permits between 2010 and 2015, of which 68\% held mussel permits for one year, and $26 \%$ renewed their permits for two to three years. Some $84 \%$ of permit sales were to men. Half of mussel permit sales were to residents in ETHEK (51\%), and a further $15 \%, 11 \%$ and $4 \%$ to residents in the coastal districts of UGU, ILEM and KING, respectively (Figure 2a). Residents from the populous inland districts of UMGUN and GAU each acquired $6 \%$ of permits sold. By age group, $66 \%$ of mussel permits were sold to fishers aged $30-59 y, 21 \%$ to those aged $\geq 60 y$, and $12 \%$ to those aged $<30$ y (Figure $2 \mathrm{~b}$ ).

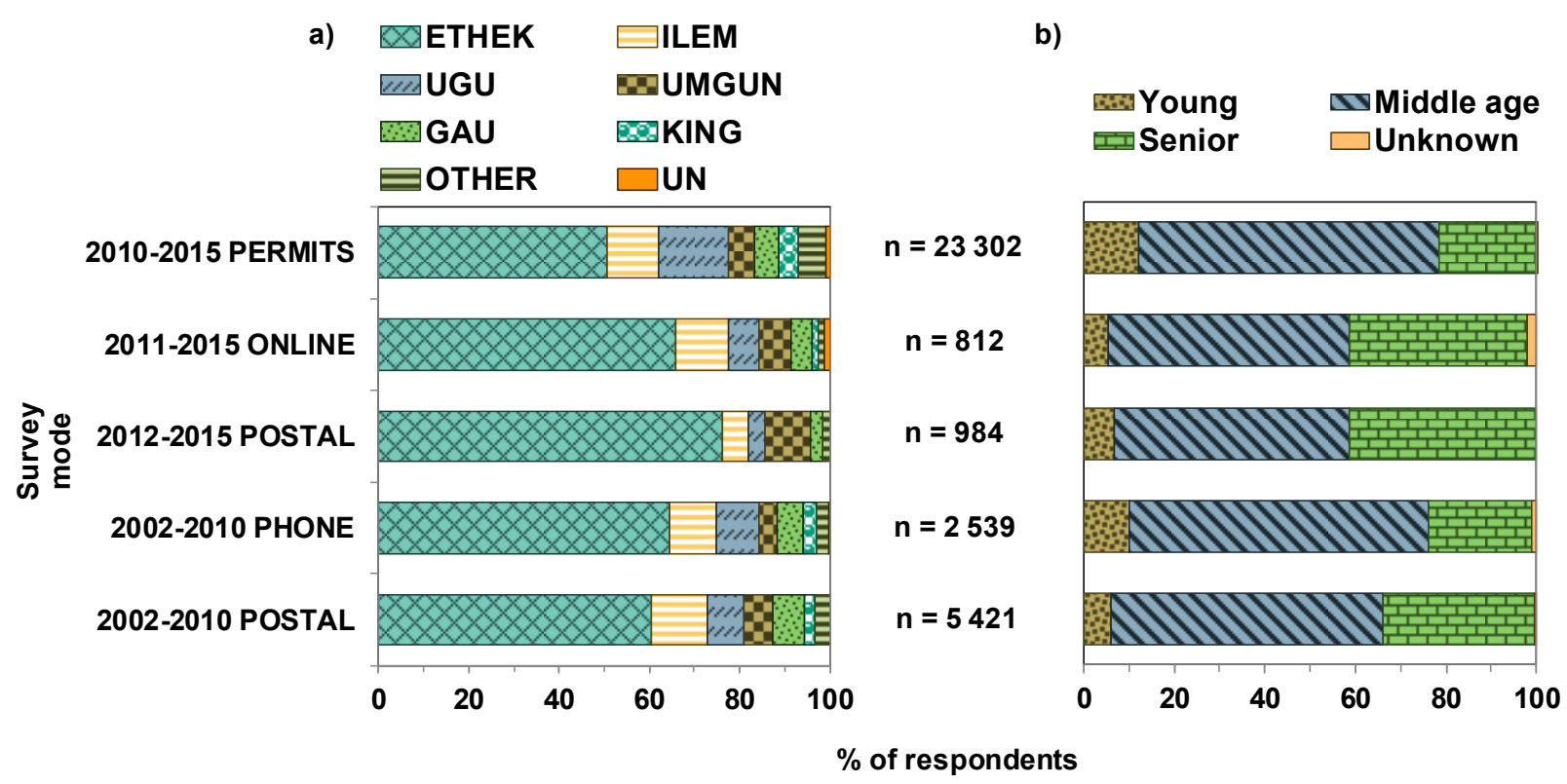

Figure 2. Permit sales in 2010-2015 by (a) residential district and (b) age group as percentage of total number of permits sold, and relative sample size per survey mode (online, postal and telephone respondents) for time periods used in the study. 


\subsection{Survey responses}

Some 4900 mussel permit holders were surveyed over 13 years. Most (58\%) completed a single quarterly survey, and most respondents (69\%) stayed in the study for one year, declining to $25 \%$ for two to three years. One respondent completed 30 surveys and remained in the study for 11 years.

Postal questionnaires were sent to an average of $859 \pm 38$ (SD) mussel permit holders per quarter between 2002 and 2009, and to $635 \pm 216$ between 2012 and 2015. The mean response rates per quarter were $25 \%$ (range 12-55\%) in 2002-2009, and 12\% (range 8-25\%) in 2012-2015. Only $49 \pm 5$ questionnaires were posted per quarter in 2010 for which no response rate could be calculated due to incomplete records, and no questionnaires were posted during 2011 and the first part of 2012. The number of postal responses remained stable at around 150-200 per quarter up to 2008, but declined sharply during 2009 and 2010, with none returned in 2011 and the first part of 2012 (Figure 3). With one exception, $<100$ responses per quarter were received after postal surveys resumed in 2012-2015.

Telephone surveys reached an average of $76 \pm 21$ of postal non-respondents per quarter between 2002 and 2009 (Figure 3). As with the postal surveys, the number of telephone responses decreased after 2008. Telephone surveys were discontinued in 2010.

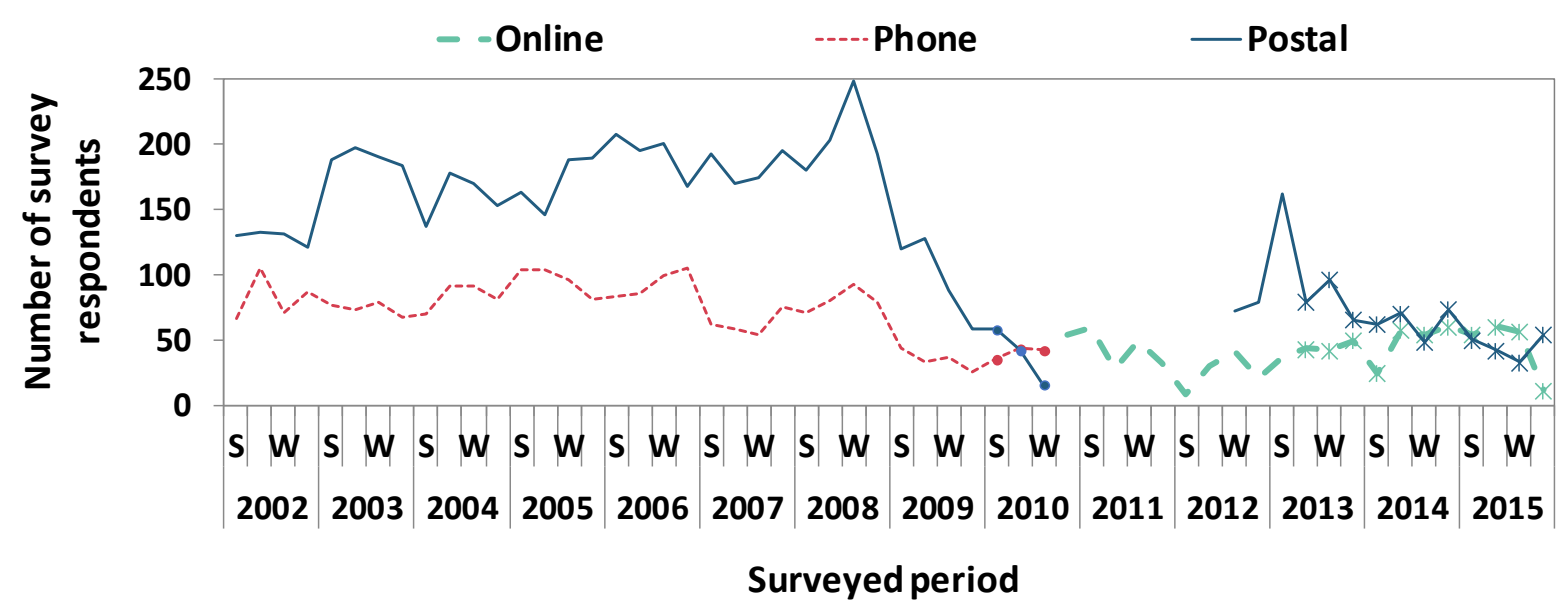

Figure 3: Postal, telephone and online respondents between April 2002 and January 2016. The recall period for surveys was three months, except for April 2010 to October 2010 surveys (marked as •) when it was longer. The wording on questionnaires changed after July 2013 (marked as *). S = summer; $\mathrm{W}=$ winter.

Email invitations to complete online surveys were sent to 490 permit holders in January 2011, increasing to 1800 per quarter by January 2016. The mailing list did not specify whether permits purchased were intended for mussel harvesting, or for other invertebrates, and an online response rate for mussel permits was therefore not calculated. Nevertheless, an average of $41 \pm 16$ mussel permit holders responded per quarterly online survey between 2011 and 2015 (Figure 3).

In relation to the numbers of permits sold per district, disproportionally more survey responses were received from residents in ETHEK (61-76\% of survey respondents), irrespective of survey mode used (Figure 2a). Proportionally fewer responses were received from UGU residents (7-9\%). Apart from the 2012-2015 postal survey, the three survey modes yielded similar response distributions across 
districts. Collectors aged $\geq 60$ y responded better to postal and online surveys than other age groups, but responses to telephone surveys were proportional to the numbers of permits sold per age group (Figure 2b).

\subsection{Trends in fisher avidity, number of outings and CPUE}

The final GLMM selected to model avidity (proportion of permits used per quarter; $n=9805$ ) included respondent identity as a random effect, and survey mode, year, season, residential district and age group as fixed effects. This combination provided the best fit (lowest AIC), and the backtransformed mean estimates, approximate standard errors (SE; Jørgensen and Pedersen 1998) and $p$-values of the main effects are shown in Table 2 . Avidity routinely peaked during summer and declined during winter (Figure 4). The proportion of avid fishers increased gradually over the sampling period, at a rate of $\sim 0.5 \%$ per year. Similar proportions of postal and online respondents were avid fishers, but telephone respondents were less avid than those surveyed with the other two modes. Permit holders from inland residential districts (GAU, UMGUN) were less avid than those from coastal districts (UGU, ETHEK, ILEM) and permit holders $<30$ y old were the most avid (Table 2 ).

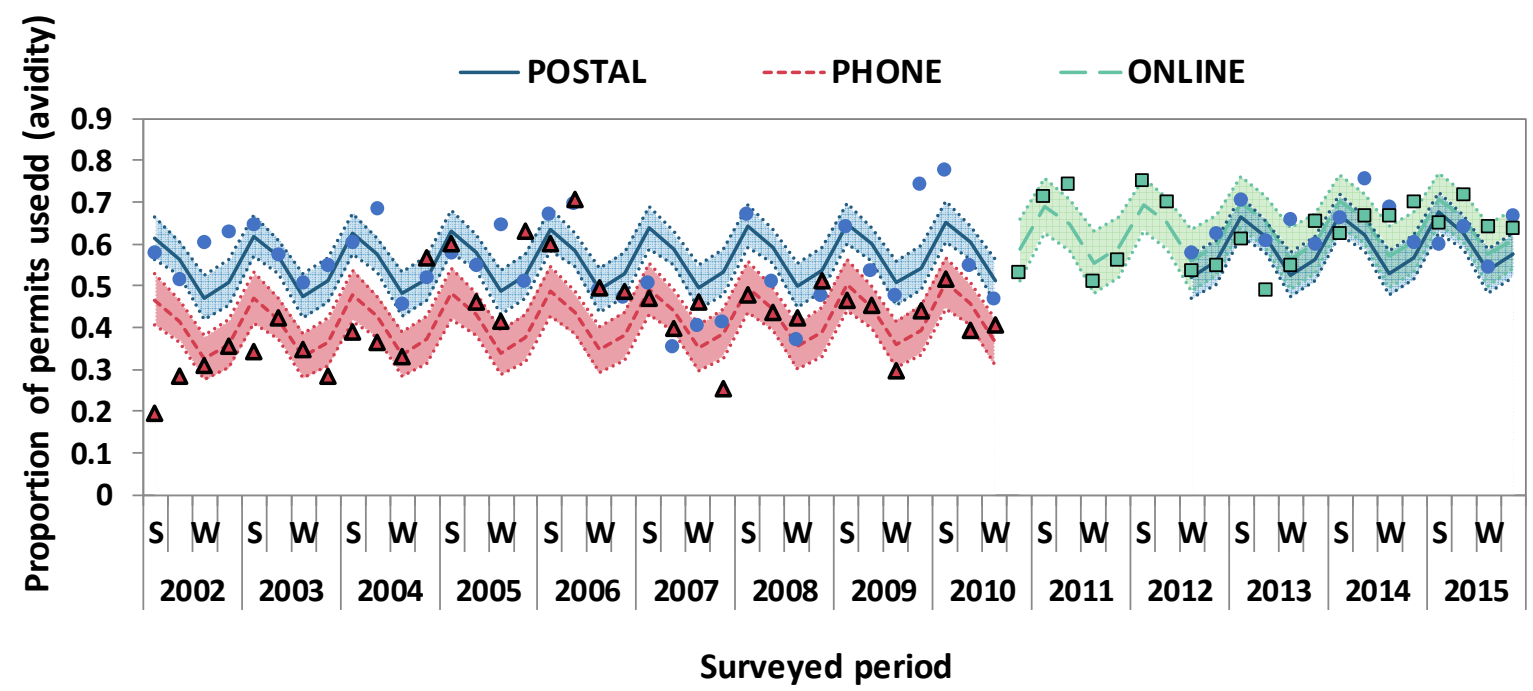

Figure 4. Fisher avidity (proportion of permits used) based on responses to postal, telephone and online surveys. The bold lines represent the best-fit model fitted to the raw data (circles = postal; triangles $=$ phone; squares $=$ online) with shaded areas indicating $95 \%$ confidence intervals. $S=$ summer; $W=$ winter. Trends were standardized for fishers aged 30-59 y old, and ETHEK residential district, and include the mean effect of individual variation (respondent ID) on avidity.

The final model used to estimate the mean number of outings per fisher per quarter relied on data from avid collectors only (those that undertook outings in a given quarter; $n=5028$ ), with respondent identity as a random effect, and year, residential district, question wording and fishing area as fixed effects (Table 2). Neither season nor age group significantly affected the number of outings. Analysis of data from postal, telephone and online surveys produced strikingly similar trends over the 13-year period (Figure 5). Respondents from all survey modes reported $0.5 \pm 0.2$ SE more outings after the 2013 change in question wording. Residential district of collectors significantly influenced the reported number of outings, and, as expected, residents of coastal districts (UGU, 
ETHEK, ILEM) undertook more outings than inland residents. In contrast, fishing area had little influence on the number of outings made by respondents. Reported outings decreased marginally ( $0.05 \pm 0.01 \mathrm{SE}$ per year), and although a significant decrease, both question wording and residential district had a far greater effect on the number of outings than year (Table 2).

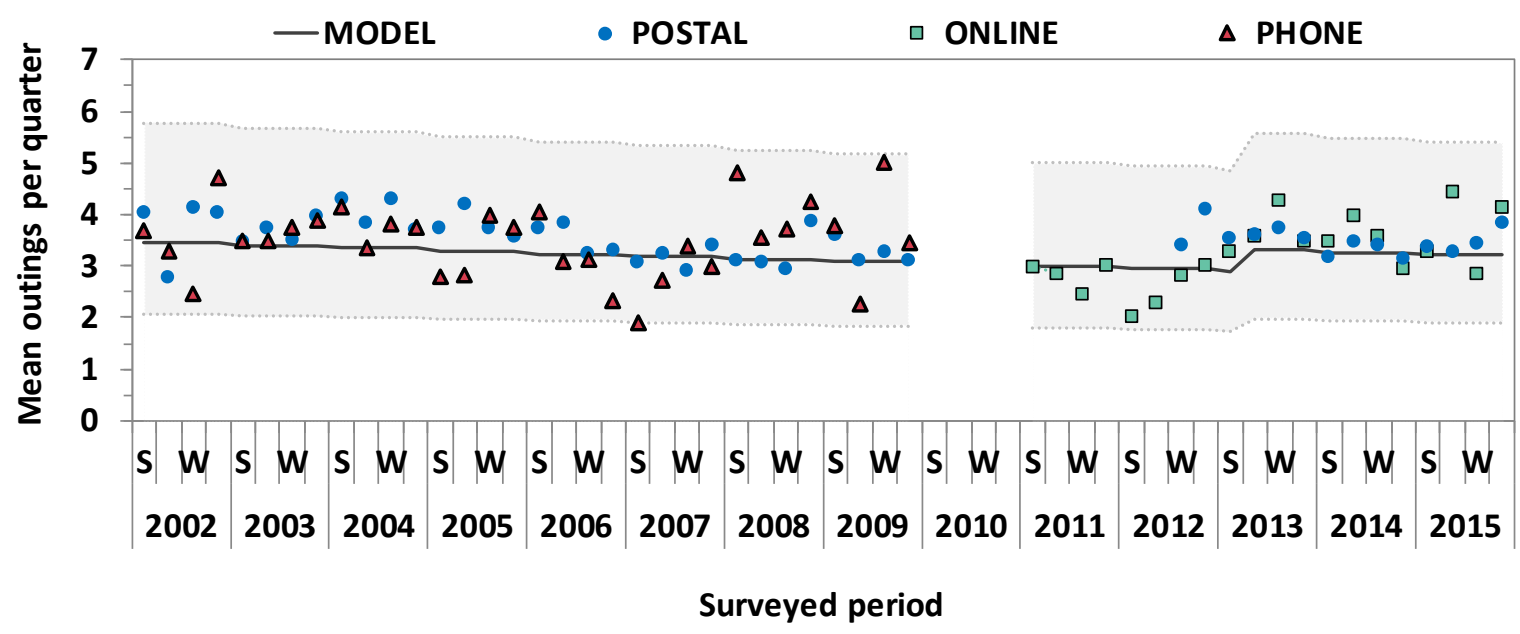

Figure 5. Mean number of outings per quarter by avid fishers, per survey mode. The best-fit model (solid line) of ETHEK residents in Central KZN to the raw data (points) is shown, with $95 \%$ confidence intervals. The model distinguished no survey mode effect and includes the mean effect of individual variation (respondent ID) on number of outings. $S=$ summer; $W=$ winter.

The CPUE data were strongly skewed towards the official bag limit of 30 mussels per outing, which was harvested in 78-83\% of outings between 2002 and 2009 and $69-70 \%$ of outings after 2010 (Appendix A; Figure A.1.). Few respondents reported a mean CPUE $>30$ mussels per outing, but this practice decreased from $4 \%$ in 2002 to $2 \%$ in 2015, partially explaining the decline in reported CPUE after 2010. The low variation in CPUE confounded model fit, despite adjustments in model structure and convergence criteria ('gamlss' procedure). The best-fitting model was statistically significant, but the AIC showed only a slight improvement over the null model, and plots of residuals fitted the infrequent CPUE values in the lower ranges poorly. In consequence, the best-fitting GAM model of mean CPUE per quarter $(n=4$ 927) predicted a constant CPUE of $28.3 \pm 0.5$ SE mussels per outing over the 13-year survey period, largely unaffected by survey mode, season, fishing area, questionnaire wording, or the residential district or age group of respondents (Table 2; Figure 6). This result implies that fishers collected the full bag limit of 30 mussels during most outings, irrespective of spatio-temporal or demographic effects. 


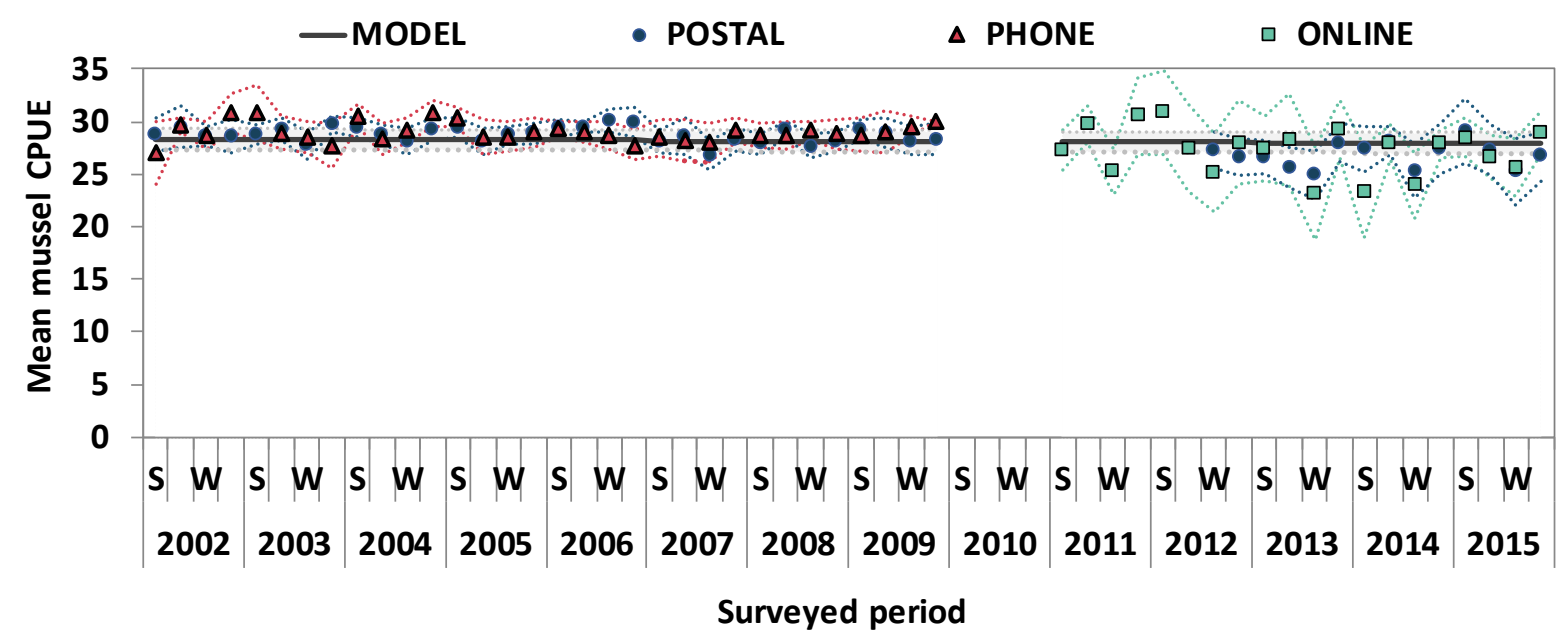

Figure 6. Mean mussel CPUE per fisher (mussels / outing $\pm 95 \%$ confidence limits) per survey mode between April 2002 and January 2016. Neither survey mode, residential district, age, fishing area or respondent ID significantly influenced the best-fit model (solid line) to the truncated raw data (points). $\mathrm{S}=$ summer; $\mathrm{W}=$ winter.

\subsection{Survey cost and efficiency}

The operating and labour costs of postal surveys were four times higher than for telephone surveys, and six times higher than for online surveys (Table 3). Postal surveys resulted in most responses (average of $81 \pm 31$ SD in 2012-2014), and online surveys the least (41 \pm 16 ; 2011-2015). Nevertheless, cost per respondent remained at least three times higher for postal than for telephone and online surveys. The time needed to conduct a postal survey was twice as long as telephone and online surveys ( 36 versus 16 days), and, in man-hours, telephone surveys were more efficient than postal and online surveys ( $2 \mathrm{~h}$ versus $>3 \mathrm{~h}$ per response).

Table 3. Cost per survey mode and response (relative to telephone survey), and time requirements. Estimated total cost of telephone survey in 2019 was US\$650.

\begin{tabular}{lccc}
\hline & Postal & Telephone & Online \\
\hline Mean number of responses/survey & $80.5+31.2$ SD & $74.3+22.4$ SD & $41.2+16.3$ SD \\
Operating cost/survey & 14.3 & 1.0 & 0.5 \\
Labour cost/survey & 1.9 & 1.0 & 0.6 \\
Total cost/survey & 3.5 & 1.0 & 0.6 \\
Total cost/response & 3.3 & 1.0 & 1.1 \\
Time spent/survey (workdays) & 36.0 & 16.3 & 16.0 \\
Time spent/response (hours) & 3.6 & 1.7 & 3.1 \\
\hline
\end{tabular}




\section{Discussion}

\subsection{Trends in fisher avidity, number of outings and CPUE}

Inter-annual trends in fisher avidity, number of outings and CPUE based on the three datasets were congruent and stable over time, without increasing or decreasing over the 13-year study period. Key findings were that permit holders conducted 3-4 outings per quarter and collected close to the daily bag limit of 30 mussels per outing. A strong seasonal trend in avidity was observed, with more fishers active during summer months. Residents from coastal districts were more likely to be active and undertook more outings per quarter than those from inland districts, and those aged $<30$ y were the most avid. With few exceptions, these properties have remained consistent between 2002 and 2015 , irrespective of the dataset interrogated.

The uniformity in number of outings over the 13-year sampling period can be explained by restricted access to mussel beds in a high-energy intertidal zone. The KZN shoreline is exposed to large swells, and mussel beds are only accessible at spring low tides when weather and sea conditions are favourable (Jackson, 1976; Tomalin and Kyle, 1998). Furthermore, recreational fishing takes place mainly over weekends or during holidays, as shown by the greater proportion of permits used over the summer holiday period. The pattern is congruent with other studies which showed that recreational fishing effort can be constrained by work and family commitments (Fedler and Ditton, 2001; Frijlink and Lyle, 2010). On-site surveys in Australia and Portugal have also shown that recreational fishing in the intertidal zone peaked during holiday periods, and when weather and tidal conditions were favourable (Kingsford et al., 1991; Rius and Cabral, 2004; Underwood and Kennelly, 1990). A combination of tidal, weather and time available for recreation therefore limits the number of days per quarter during which mussel outings can be made, placing a cap on collecting opportunities, and homogenizing fishing effort over longer time frames.

Strong seasonal trends in fisher avidity are best explained by more favourable weather during late summer months, but also by seasonality in the physical condition of mussels. Brown mussels spawn between June and November, when they lose flesh weight and become less appealing as seafood (Berry, 1978). Gamete production starts in February and gonads are at their largest in March to May, thus explaining the increased fisher avidity between January to June, compared to July to December. When inactive fishers were excluded from the outings model, season became an insignificant predictor of the number of outings undertaken. This suggests that an avid group of fishers remain active throughout the year, maintaining a relatively constant number of outings per quarter, irrespective of the season.

The mean CPUE closely reflected the daily bag limit of 30 mussels over the entire surveyed period, suggesting that fishers were able to collect the bag limit during most outings, irrespective of year, season, fishing area or age group. A similar trend was observed prior to 1998, when the mussel bag limit was 50, and the nominal CPUE remained stable at $\sim 46$ mussels per outing (Robertson, 2003). Creel patrols by compliance officers during the same period, also reported mussel catches close to the daily bag limit (Steyn, 2017), suggesting that the data reported by the questionnaire surveys were realistic. Nevertheless, Barescut et al. (2011) showed that censored regression loses its efficacy when $80 \%$ or more of observations are close to a censoring limit, a factor that almost certainly affected the present CPUE trend (Figure 6). 
The CPUE index appeared to be unable to track changes in the relative abundance of mussels at the coarse spatio-temporal scale investigated, most likely because of hyperstability (CPUE remains stable while stock abundance declines; Erisman et al., 2011). In such cases, the CPUE decreases sharply once the stock is close to depletion - i.e., when there are so few mussels on a reef that the bag limit cannot be reached, even when extending the duration of the outing. In its present form, the CPUE is therefore a poor indicator of the mussel stock status in KZN (see also Tomalin and Kyle, 1998; Robertson, 2003). Catch per hour may better reveal changes in abundance, but recall bias is likely to be high for such a statistic. Instead of using a CPUE index based on off-site surveys to measure relative abundance trends over time, we suggest that mussel densities at reference sites are determined using counts and mussel size composition in random quadrats (see McQuaid et al., 2000; Robertson, 2003), and comparing the results at a finer spatio-temporal scale.

The alternative hypothesis, that the CPUE index is a true reflection of mussel abundance, is less likely to be true, despite a mussel life-history that includes broadcast spawning and rapid growth. Tomalin and Kyle (1998) found high recreational fishing mortality in central KZN, with deleterious effects on some reefs, and recommended that fishing effort should be reduced. Reefs that were inaccessible to recreational fishers were also denuded of mussels, presumably as a result of natural causes. During 2002-2015, field surveys of mussel beds in central KZN showed great variation in mussel cover over time, and between mussel beds (range: 10-93\% coverage; Steyn and Schleyer, 2012; unpub. data ES). It is therefore clear that spatio-temporal trends in mussel abundance are common, even though this is not apparent from the CPUE index.

\subsection{Sources of survey bias}

Several factors may have affected the survey data. The pool of permit holders available for sampling was limited to $3000-5000$ mussel permits sold per year and, because of incomplete record-taking, postal contact details were not available for them all. Some permit holders were therefore surveyed repeatedly during a year (i.e. during different quarters), becoming non-responsive over time.

Response rates in postal survey (12-25\%) were lower than typical rates seen in the literature (2658\%, Baharthah, 2007; McClanahan and Hansen, 2005; Seppänen and Toivonen, 2010; Tarrant et al., 1993), but higher than $7 \%$ cited by Zarauz et al. (2015). The low response rate in the present study can also be explained by low collection avidity (permit bought but not used). Inactive fishers are less likely to respond to surveys in which they have little interest (Edwards et al., 2002; Fisher, 1996; Thomson, 2013). Response rates were also affected by recreational fishers that disagreed with licensing and fishing regulations (pers. obs. ES) and declined to participate in surveys. Despite the low response rates, the analyses yielded clear trends in fisher avidity, number of outings and CPUE, irrespective of model structure.

The postal survey data exhibited a non-response bias, in which fewer responses were received from inactive- than avid fishers. The difference in fisher avidity between postal respondent and nonrespondent groups could clearly be seen in the data of follow-up telephone surveys, in which postal non-respondents consistently reported lower avidity than postal survey respondents (see Figure 4). This result corresponded with surveys of other fisheries (Barrett et al., 2017; Connelly et al., 2000; Thomson, 2013), where active participants were more likely to respond than those that fished rarely. Nevertheless, the catch per outing (and hence CPUE) reported by avid- and less active fishers was similar, with both groups reporting a full daily bag limit on most occasions. 
A mode bias (in which survey modes sample fisher populations that differ in demographics and behaviour) was observed, with permit holders $\geq 60$ y old more likely to respond to postal and online surveys than those aged $<30 \mathrm{y}$. In contrast, the follow-up telephone surveys were effective in sampling permit holders $<30$ y old, resulting in an age distribution of sampled collectors corresponding with that of the 2010-2015 permit holder data. An over-representation of older respondents in postal- and online surveys is common (Fisher, 1996; Frijlink and Lyle, 2010; Gigliotti and Henderson, 2015), because they may have more time to complete surveys (Gigliotti and Henderson, 2015) or have a longer history and greater interest in the fishery (Edwards et al., 2002; Groves et al., 2004). In contrast, younger non-respondents will have a shorter history in the fishery and may have other family and work commitments (Gigliotti and Henderson, 2015). The absence of a more prominent mode bias may also reflect an overlap, in which the same fishers were sampled using different modes, because many online respondents were recruited from original postal and telephone surveys.

Uneven sampling coverage of residential districts was mitigated within the modelling framework. Residents from ETHEK were over-represented in samples (all three modes), whereas those from coastal areas at UGU and KING were under-represented. The imbalance in sampling density reflected differences in postal delivery systems, allowing for home delivery in ETHEK, but only at a central post box system in UGU and KING. Permit application forms did not make provision for central post box information, and postal questionnaires were therefore overwhelmingly sent to ETHEK addresses. In a knock-on effect, telephone surveys targeted postal non-respondents (i.e. mainly ETHEK permit holders) and online addresses were obtained mainly from prior postal or telephone surveys (also mainly ETHEK residents). It was therefore unsurprising that the three survey modes exhibited similar geographical bias in sampling effort.

A recall bias (inability of respondents to recall events in the past) may have affected the reported number of outings and CPUE, even though recall periods were restricted to three months. Fishers typically become more likely to overestimate effort (number of outings) when recall periods increase in duration (Connelly and Brown, 1995) and Tarrant et al. (1993) found that even three-month recall periods in postal surveys could double reported outings, compared to diaries. Fishers that undertake frequent outings are also more likely to overestimate their effort, compared to those who conduct fewer outings (Connelly and Brown, 1995). Our study did not test for recall bias, because the individual effort of mussel fishers was low (3-4 outings per quarter), and unlikely to have influenced recall greatly.

The change in question wording in 2013 gave rise to a minor, but statistically significant increase in the modelled number of outings per quarter. Some respondents in surveys prior to the wording change presumably misinterpreted the initial question, and provided inaccurate answers. On its own, the wording change potentially explains the increase in collection effort (number of outings) after 2012 (see Figure 5). Overall, the congruence of inter-annual trends suggests that broad trends in avidity, number of outings and CPUE were not substantially distorted by changes in sampling.

\subsection{Future research}

Based on lower costs and man-hours required, and on rapid growth in telecommunication technology, online surveys followed up by telephone surveys of non-respondents need to be considered as future survey modes. Online surveys cost the least to undertake, but had low 
response rates in the present study, concordant with results from other studies (Fan and Yan, 2010; Gigliotti and Henderson, 2015; Shih and Fan, 2008; Zarauz et al., 2015). The geographical coverage of online surveys in our study was restricted, because email addresses were not available for most of the permit holders. Furthermore, online response rates decreased sharply when it was the only survey mode used. Mixed-mode surveys based on a combination of survey modes have been shown to achieve higher response rates (Barrett et al., 2017; De Leeuw, 2005; Fowler et al., 2002; Wallen et al., 2016). Changing to a strategy of online and telephonic follow-up surveys will need considerable preparation, including capturing the email addresses of fishers when they buy permits at post offices; extending geographical coverage more evenly across residential districts; popularising online questionnaires through further development of real-time applications and advertising, and by improving feed-back summaries of results to respondents (Gigliotti and Henderson, 2015).

Verification, or ground-truthing of data collected by off-site surveys is required, through on-site sampling of recreational fishing activities and catches. On-site sampling is particularly important in this fishery, because many recreational fishers do not have online access, or are distrustful of online surveys, and they are therefore not sampled at present. On-site sampling is also a better method for monitoring the subsistence fishery, albeit small and localized.

\subsection{Conclusion}

In conclusion, postal-, telephone and online surveys produced consistent estimates of fisher avidity, number of outings undertaken, and CPUE over the 13-year sampling period. All three trends were stable over time, with avidity increasing during summer, but the number of outings restricted by the limited time available during spring low tides. The off-site surveys provided important information on the behaviour of recreational fishers, and could distinguish the effects of age group, residential district, fishing area and season on fishing effort and catches. However, the CPUE trend was constrained by the bag limit, and censored regression models were unable to trace the relative abundance of mussels at the spatio-temporal scale investigated. Our study provides the only longterm record of the recreational mussel fishery in KZN. A mixed-mode strategy based on online surveys with telephonic follow-up of non-respondents is proposed to improve future surveys, supplemented with on-site sampling to verify the results from the questionnaire surveys and provide relative abundance indices.

\section{Acknowledgements}

We are thankful to the numerous individuals who assisted with data management and survey administration, particularly Gareth Jordaan and the late lan Brash. A special thank you goes to the anglers and invertebrate collectors who have supported this research programme for more than 15 years. This study was partially funded by the Department of Agriculture, Forestry and Fisheries (DAFF; Project number RD76), South Africa. 


\section{References}

1. Baharthah, T., 2007. Comparison of three survey methods applied to the recreational rock lobster fishery of Western Australia. MSc thesis, Edith Cowan University, Perth: 171p. https://ro.ecu.edu.au/theses/2

2. Barescut, J., Lariviere, D., Stocki, T., Wood, M. D., Beresford, N. A., Copplestone, D. 2011. Limit of detection values in data analysis: Do they matter? Radioprotection 46(6), S85-S90. https://doi.org/10.1051/radiopro/20116728s

3. Barrett, B.N., Van Poorten, B., Cooper, A.B., Haider, W., 2017. Concurrently assessing survey mode and sample size in off-site angler surveys. North American Journal of Fisheries Management 37 (4): 756-767. https://doi.org/10.1080/02755947.2017.1324543

4. Bates, D., Maechler, M., Bolker,B., Walker, S., 2015. Fitting Linear Mixed-Effects Models Using Ime4. Journal of Statistical Software 67 (1): 1-48. https://doi.org/10.18637/jss.v067.i01

5. Berry, P.F., 1978. Reproduction, growth and production in the mussel Perna perna (Linnaeus) on the east coast of South Africa. Oceanographic Research Institute, Durban: 28p. (ORI Investigational Report 48)

6. Cole, T., Green, P.J., 1992. Smoothing Reference Centile Curves: The LMS Method and Penalized Likelihood. Statistics in Medicine 11:1305-1319. https://doi.org/10.1002/sim.4780111005

7. Connelly, N.A., Brown, T.L. 1995. Use of angler diaries to examine biases associated with $12-$ month recall on mail questionnaires. Transactions of the American Fisheries Society 124:413422. https://doi.org/10.1577/1548-8659(1995)124\%3C0413:UOADTE\%3E2.3.CO;2

8. Connelly, N.A., Brown, T.L., Knuth, B.A., 2000. Assessing the relative importance of recall bias and nonresponse bias and adjusting for those biases in statewide angler surveys. Human Dimensions of Wildlife: An International Journal 5 (4): 19-29. http://dx.doi.org/10.1080/10871200009359192

9. De Leeuw, E., 2005. To mix or not to mix data collection modes in surveys. Journal of Official Statistics 21 (2): 233-255.

10. De Leeuw, E., De Heer, W., 2002. Trends in household survey nonresponse: A longitudinal and international comparison. In: Groves, R.M., Dillman, D.A., Eltinge, J.L., Little, R.J.A. (Eds.) Survey nonresponse. Wiley, New York: 41-54.

11. Edwards, P., Roberts, I., Clarke, M., DiGuiseppi, C., Pratap, S., Wentz, R., Kwan, I., 2002. Increasing response rates to postal questionnaires: systematic review. BMJ 324: 1183-1191. https://doi.org/10.1136/bmj.324.7347.1183

12. Erisman, B.E., Allen, L.G., Claisse. J.T., Pondella. D.J., Miller, E.F., Murray, J.H., 2011. The illusion of plenty: hyperstability masks collapses in two recreational fisheries that target fish spawning aggregations. Canadian Journal of Fisheries and Aquatic Sciences 68 (10): 1705-1716. https://doi.org/10.1139/f2011-090

13. Fan, W., Yan, Z., 2010. Factors affecting response rates of the web survey: A systematic review. Computers in Human Behavior 26: 132-139. https://doi.org/10.1016/i.chb.2009.10.015

14. Fedler, A.J., Ditton, R.B., 2001. Dropping out and dropping in: A study of factors for changing recreational fishing participation. North American Journal of Fisheries Management 21(2): $283-$ 292. https://doi.org/10.1577/1548-8675(2001)021\%3C0283:DOADIA\%3E2.0.CO;2

15. Fisher, M.R., 1996. Estimating the effect of nonresponse bias on angler surveys. Transactions of the American Fisheries Society 125 (1): 118-126. https://doi.org/10.1577/15488659(1996)125\%3C0118:ETEONB\%3E2.3.CO;2 
16. Fowler, F.F., Gallagher, P.M., Stringfellow, V.L., Zaslavsky, A.M., Thompson, J.W., Cleary, P.D. 2002. Using telephone interviews to reduce nonresponse bias to mail surveys of health plan members. Medical Care 40(3): 190-200. https://doi.org/10.1097/00005650-200203000-00003

17. Frijlink, S., Lyle, J.M., 2010. An evaluation of motivations, attitudes and awareness of Tasmanian recreational fishers. Tasmanian Aquaculture and Fisheries Institute, Hobart: 56p. (TAFI report)

18. Gigliotti, L.M., Henderson, K.R., 2015. Reasons anglers did not respond to an internet survey and evaluation of data quality. Proceedings of the South Dakota Academy of Science 94: 155-170.

19. Groves, R.M., 2006. Nonresponse rates and nonresponse bias in household surveys. Public Opinion Quarterly 70 (5) Special Issue: 646-675. https://doi.org/10.1093/poq/nfl033

20. Groves, R.M., Presser, S., Dipko, S., 2004. The role of topic interest in survey participation decisions. Public Opinion Quarterly 68 (1): 2-31. https://doi.org/10.1093/poq/nfh002

21. Harris, C.C., Bergerson, E.P., 1985. Survey on demand for sport fisheries: problems and potentialities for its use in fishery management planning. North American Journal of Fisheries Management 5 (3A): 400-410. https://doi.org/10.1577/15488659(1985)5<400:SODFSF>2.0.CO;2

22. Harris, J.M., Branch, G.M., Clark, B.M., Sibiya, S.C., 2007. Redressing access inequities and implementing formal management systems for marine and estuarine subsistence fisheries in South Africa. In: McClanahan, T.R., Castilla, J.C. (Eds.), Fisheries management: progress towards sustainability. Blackwell Publishing, Oxford, UK: 112-138.

23. Hartnill, B.W., Edwards, C.T.T., 2015. Comparison of recreational harvest estimates provided by onsite and offsite surveys: detecting bias and corroborating estimates. Canadian Journal of Fisheries and Aquatic Sciences 72 (9): 1379-1389. https://doi.org/10.1139/cjfas-2014-0451

24. Jackson, L.F., 1976. Aspects of the intertidal ecology of the east coast of South Africa. Oceanographic Research Institute, Durban: 72p. (ORI Investigational Report 46)

25. Jørgensen, E., Pedersen, A.R., 1998. How to obtain those nasty standard errors from transformed data-and why they should not be used. Department of Biometry and Informatics, Danish Institute of Agricultural Science, Tjele: 20p. (International Report 7)

26. Kingsford, M.J., Underwood, A.J., Kennelly, S.J., 1991. Humans as predators on rocky reefs in New South Wales, Australia. Marine Ecology Progress Series 72 (1-2): 1-14.

27. Kruger, A., Schleyer, M.H., 2003. Mail and telephone surveys of permit-holders to obtain recreational invertebrate fisheries catch statistics for 2002. Oceanographic Research Institute, Durban: 12p. (ORI Data Report 2003/6)

28. Kruger, A., Tomalin, B.J., 1996. Usage of mussel and crayfish licenses and the attitudes of licence holders in KwaZulu-Natal: Results from a telephone survey for 1994 and 1995. Oceanographic Research Institute, Durban: 13p. (ORI Data Report 96/4)

29. Lesser, W.M., Newton, L.D., Yang, D.K., Sifneos, J.C., 2016. Mixed-mode surveys compared with single mode surveys: Trends in responses and methods to improve completion. Journal of Rural Social Sciences 31 (3): 7-34.

30. McQuaid, C.D., Lindsay, J.R., Lindsay, T.L., 2000. Interactive effects of wave exposure and tidal height on population structure of the mussel Perna perna. Marine Biology 137 (5-6): 925-932. https://doi.org/10.1007/s002270000398

31. McClanahan, D.R., Hansen, M.J., 2005. A statewide mail survey to estimate 2000-2001 angler catch, harvest, and effort in Wisconsin. Wisconsin Department of Natural Resources, Stevens Point: 48p. (Fisheries Management Report 151) 
32. Pollock, K.H., Jones, C.M., Brown, T.L., 1994. Angler survey methods and their applications in fisheries management. American Fisheries Society, Bethesda: 371p. (American Fisheries Society Special Publication 25)

33. Pradervand, P., Govender, R.D., 2001. Recreational angling data collection by KZN Wildlife: 2000 annual report. South African Association for Marine Biological Research, Durban: 15p. (SAAMBR Data Report 2001/2)

34. R Core Team, 2016. R: A Language and Environment for Statistical Computing. R Foundation for Statistical Computing, Vienna, Austria. https://www.R-project.org/

35. Rigby, R.A., Stasinopoulos, D.M., 2005. Generalized additive models for location, scale and shape. Applied Statistics 54 (3): 507-554. https://doi.org/10.1111/j.1467-9876.2005.00510.x

36. Rius, M., Cabral, N., 2004. Human harvesting of Mytilus galloprovincialis Lamarck, 1819, on the central coast of Portugal. Scientia Marina, 68 (4): 545-551.

37. Rius, M., Kaehler, S., McQuaid, C.D., 2006. The relationship between human exploitation pressure and condition of mussel populations along the south coast of South Africa. South African Journal of Science, 102 (3): 130-136. https://eprints.soton.ac.uk/id/eprint/355041

38. Robertson, W.D., 2003. Management procedures for small-scale invertebrate fisheries on the KwaZulu-Natal coast, South Africa. PhD thesis, University of KwaZulu-Natal, Durban: 353p.

39. Seppänen, E., Toivonen, A.L., 2010. Understanding recreational fishing in the perspective of second homes and tourism. Nordia Geographical Publications 39 (1): 15-26.

https://nordia.journal.fi/article/view/75964/37334

40. Shih, T., Fan, X., 2008. Comparing response rates from web and mail surveys: A meta-analysis. Field Methods 20 (3): 249-271. https://doi.org/10.1177/1525822X08317085

41. Sink, K.J., Branch, G.M., Harris, J.M., 2005. Biogeographic patterns in rocky intertidal communities in Kwazulu-Natal, South Africa. African Journal of Marine Science 27 (1): 81-96. https://doi.org/10.2989/18142320509504070

42. Stasinopoulos, D.M., Rigby, R.A., 2018. Generating and Fitting Truncated 'gamlss.family' Distributions. R package version 5.1-0. https://cran.r-project.org/web/packages/gamlss.tr/gamlss.tr.pdf

43. Steyn, E., 2016. Recreational shellfish collection in KZN based on questionnaire surveys: 20132014. Oceanographic Research Institute, Durban: 40p. (ORI Unpublished Report 330)

44. Steyn, E., 2017. Invertebrate catches recorded during Ezemvelo KwaZulu-Natal marine and estuarine patrols. Oceanographic Research Institute, Durban: 67p. (ORI Unpublished Report 334)

45. Steyn, E., Schleyer, M.H., 2012. Long-term monitoring of Umhlanga / Umdloti mussel beds: The impact of the Umdloti mussel management area. Oceanographic Research Institute, Durban: 15p. (ORI Unpublished Report 301)

46. Steyn, E., Schleyer, M.H., 2014. Recreational shellfish collection in KZN: Data from 2008-2012 questionnaire surveys. Oceanographic Research Institute, Durban: 39p. (ORI Unpublished Report 313)

47. Tarrant, M.A., Manfredo, M.J., Bayley, P.B., Hess, R., 1993. Effects of recall bias and nonresponse bias on self-report estimates of angling participation. North American Journal of Fisheries Management 13 (2): 217-222. https://doi.org/10.1577/15488675(1993)013\%3C0217:EORBAN\%3E2.3.CO;2

48. Thomson, A.W., 2013. An estimator to reduce mail survey nonresponse bias in estimates of recreational catch: a case study using data from the Panulirus cygnus fishery of Western Australia. PhD thesis, Curtin University, Perth: 213p. 
49. Tomalin, B.J., 1993. Estimates of non-commercial coastal invertebrate landings in Natal based on licence returns: 1963 to 1992. Oceanographic Research Institute, Durban: 19p. (ORI Data Report 93/5)

50. Tomalin, B.J., Kruger, A., 2000. Estimated landings of coastal invertebrates by recreational collectors in KwaZulu-Natal, 1964-1998. South African Association for Marine Biological Research, Durban: 20p. (SAAMBR Data Report 2000/1)

51. Tomalin, B.J., Kyle, R., 1998. Subsistence and recreational mussel (Perna perna) collecting in KwaZulu-Natal, South Africa: fishing mortality and precaution management. South African Journal of Zoology 33 (1): 12-22. https://doi.org/10.1080/02541858.1998.11448448

52. Underwood, A.J., Kennelly, S.J., 1990. Pilot studies for designs of surveys of human disturbance of intertidal habitats in New South Wales. Australian Journal of Marine and Freshwater Research, 41 (1): 165-173. https://doi.org/10.1071/MF9900165

53. Van der Hammen, T., De Graaf, M., Lyle, J.M., 2016. Estimating catches of marine and freshwater recreational fisheries in the Netherlands using an online panel survey. ICES Journal of Marine Science 73 (2): 441-450. https://doi.org/10.1093/icesjms/fsv190

54. Venables, W.N., Ripley, B.D., 2002. Modern Applied Statistics with S. Fourth Edition. Springer, New York. ISBN 0-387-95457-0

55. Wallen, K.E., Landon, A.C., Kyle, G.T., Schuett, M.A., Leitz, J., Kurzawski, K., 2016. Mode effect and response rate issues in mixed-mode survey research: Implications for recreational fisheries management. North American Journal of Fisheries Management 36 (4): 852-863. https://doi.org/10.1080/02755947.2016.1165764

56. WIOFish, 2013. A catalogue of fisheries from the western Indian Ocean. http://www.wiofish.org (accessed 27 May 2019).

57. Zarauz, L., Ruiz, J., Urtizberea, A., Andonegi, E., Mugerza, E., Artetxe, I., 2015. Comparing different survey methods to estimate European sea bass recreational catches in the Basque Country. ICES Journal of Marine Science 72 (4): 1181-1191. https://doi.org/10.1093/icesjms/fsv054

58. Zeileis, A., Hothorn, T., 2002. Diagnostic Checking in Regression Relationships. R News 2 (3), 710. https://CRAN.R-project.org/doc/Rnews/ 
Appendix A. Supplementary data

Questionnaire A.1

QUESTIONNAIRE NUMBER:

Summer Survey - Invertebrate Catch Statistics

OCEANOGRAPHIC RESEARCH INSTITUTE

JANUARY 2013

Return to: Invertebrate Catch Statistics, Oceanographic Research Institute, P.O. Box 10712, Marine Parade, 4056

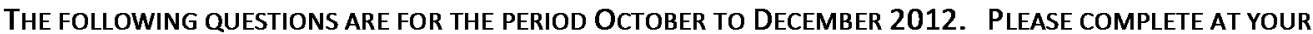
EARLIEST CONVENIENCE AND MAIL TO THE ABOVE ADDRESS. A PREPAID RETURN ENVELOPE IS PROVIDED.

\section{Thank You For Your Assistance}

1. Please provide a phone number where you can be contacted between the 13th and the 31st of January 2014 should you be a prize winner in the lucky draw:

2. If YOU HAVE AN E-MAIL ADDRESS, PLEASE WOULD YOU PROVIDE IT?

3. Please indicate Which PeRmits you held in 2011 and dURINg OCt-DeC 2012.

EAST COAST ROCK LOBSTER (PERMIT 07)

MUD CRAB (SCYLLA SERRATA - PERMIT 08)

Mollusc/General bait (PERMit 09)

MUSSEL (PERMIT 13)

OYSTER (PERMIT 14)

OTHER (PLEASE SPECIFY)

4. ANSWER ONIY If YOU HELD AN EAST COAST ROCK LOBSTER PERMIT DURING OCT-DEC 2012. Please Indicate the Method YOU USE TO COllect ROCK LOBSTERS.

SNORKEL

TRAP HOOK AND LNE

Other (PLEASE SPECIFY)

5. Answer only if You held a MUSSEL PeRmit dURINg OCt-DeC 2012.

When do you mainly collect mussels?

\begin{tabular}{|c|c|c|}
\hline All year & Summer & Autumn \\
\hline Winter & Spring & Only holidays \\
\hline
\end{tabular}

6. ANSWER ONLY IF YOU HELD A MOLLUSC / GENERAL BAIT PERMIT DURING OCT-DEC 2012. Which organisms do you collect on the mollusc / general bait permit?

$\begin{array}{ll}\text { Ghost crab } \square & \text { Mussel } \\ \text { Rock crabs } \square & \text { Octopus } \\ \text { Mole crab } \square & \text { Mud prawn } \\ \text { (Sea lice) } & \begin{array}{l}\text { (greenish-black, } \\ \text { both nippers same size) }\end{array}\end{array}$

Oyster

Redbait

Sand prawn

(white body, one nipper bigger than other)

Other (please specify) 
Questionnaire A.1 continued

7. For All Permit-Holders: Catch Data

Please answer the following questions about the invertebrate catches you made during OctDec2012. Add catches of species not listed at the bottom of the table.

\begin{tabular}{|c|c|c|c|c|c|c|}
\hline SPEcies Collected & $\begin{array}{l}\text { MaIN } \\
\text { COLLECTION } \\
\text { STIE }\end{array}$ & $\begin{array}{l}\text { NUMBER OF } \\
\text { OUTINGS } \\
\text { DURING OCT- } \\
\text { Dec } 20122^{*}\end{array}$ & $\begin{array}{l}\text { Average } \\
\text { DURATION OF } \\
\text { OUTING }\end{array}$ & $\begin{array}{c}\text { AVERAGE } \\
\text { CATCH PER } \\
\text { OUTING, } \\
\text { EXCLUDING } \\
\text { OUTINGS WHEN } \\
\text { NO CATCHES } \\
\text { WERE MADE * }\end{array}$ & $\begin{array}{l}\text { NUMBER OF } \\
\text { OUTINGS ON } \\
\text { WHICH } \\
\text { NOTHING WERE } \\
\text { COLLECTED * }\end{array}$ & $\begin{array}{l}\text { DID EKZN } \\
\text { WILDLIFE STAFF } \\
\text { INSPECT } \\
\text { CATCHES OR } \\
\text { PERMTS? }\end{array}$ \\
\hline \multicolumn{7}{|l|}{$\begin{array}{l}\text { EAST COAST ROCK } \\
\text { LOBSTER }\end{array}$} \\
\hline \multicolumn{7}{|l|}{ MUD CRAB } \\
\hline \multicolumn{7}{|l|}{ MusSeL } \\
\hline \multicolumn{7}{|l|}{ OYSTER } \\
\hline \multicolumn{7}{|l|}{$\begin{array}{l}\text { SAND PRAWN (WHITE } \\
\text { BODY, ONE NIPPER } \\
\text { BIGGER THAN OTHER) } \\
\end{array}$} \\
\hline \multicolumn{7}{|l|}{$\begin{array}{l}\text { MUD PRAWN } \\
\text { (GREENISH-BLACK, } \\
\text { BOTH NIPPERS SAME } \\
\text { SIZE) }\end{array}$} \\
\hline \multicolumn{7}{|l|}{ Octopus } \\
\hline \multicolumn{7}{|l|}{ RedBatT } \\
\hline \multicolumn{7}{|l|}{$\begin{array}{l}\text { MoLE CRABS (SEA } \\
\text { LICE) }\end{array}$} \\
\hline \multicolumn{7}{|l|}{ GHOST CRABS } \\
\hline \multicolumn{7}{|l|}{ Rock CRABS } \\
\hline & & & & & & \\
\hline & & & & & & \\
\hline
\end{tabular}

* How to complete table: If you made 5 outings, collecting 4 animals on $1^{\text {st }}$ outing, 3 animals on $2^{\text {nd }}$ outing, 5 animals on $3^{\text {rd }}$ outing and no animals on $4^{\text {th }}$ and $5^{\text {th }}$ outings - then number of outings is 5 , average catch per outing is $4=\left(\frac{4+3+5}{3}\right)$ and number of outings on which nothing were collected is 2 .

8. Please add any further comments you wish to make below: 


\section{Questionnaire A.2}

QUESTIONNAIRE NUMBER:

\section{Spring Survey - Invertebrate Catch Statistics OCEANOGRAPHIC RESEARCH INSTITUTE OCTOBER 2014}

Return to: Invertebrate Catch Statistics, Oceanographic Research Institute, P.o. Box 10712, Marine Parade, 4056

The following Questions are for the Period 1 July to 30 SePtember 2014. Please complete at your EARLIEST CONVENIENCE AND MAIL TO THE ABOVE ADDRESS. A PREPAID RETURN ENVELOPE IS PROVIDED.

THANK YOU For YoUR ASSISTANCE

1. Please provide a phone number where you can be contacted between the 12th and the 31st of January 2015 should you be a prize winner in the lucky draw:

2. IF YOU HAVE AN E-MAIL ADDRESS, PLEASE WOULD YOU PROVIDE IT?

3. Please indicate Which Permits you held during JUL-Sep 2014. TiCK the APPRopriate blocks.

\begin{tabular}{|c|c|c|c|c|c|}
\hline EAST COAST ROCK LOBSTER (PERMIT 07) & YES & No & MUSSEL (PERMIT 13) & YES & No \\
\hline MUD CRAB (SCYLLA SERRATA - PERMIT 08) & YES & No & OYSTER (PERMIT 14) & YES & No \\
\hline MolLusc/GENERAL BAIT (PERMIT 09) & YES & No & & & \\
\hline
\end{tabular}

4. A) DID EKZNWILDLIFE INSPECT ANY OF YOUR SHELLFISH PERMITS (PERMITS 7, 8, 9, 13, 14) OR CATCHES DURING JUL-SEP 2014 ? TICK THE APPROPRIATE BLOCKS.

B) IF YES, HOW MANY TIMES WERE PERMITS / CATCHES INSPECTED DURING JUL-SEP 2014?

5. ANSWER ONLY If YOU HELD AN EAST COAST ROCK LOBSTER PERMIT DURING JULY TO SEPTEMBER 2014. PLEASE INDICATE THE METHOD YOU USE TO COLLECT ROCK LOBSTERS. TICK THE APPROPRIATE BLOCKS.
SNORKEL
TraP HOOK AND LINE
OtHeR (PLEASE SPECIFY)

6. ANSWER ONLY If YOU HELd A MUSSEL PERMIT DURING JULy to SEPTEMBER 2014. When do you mainly collect mussels? Tick the appropriate blocks.
All year
Summer
Autumn
Winter
Spring
Only holidays

7. ANSWER ONLY IF YOU HELD A MOLLUSC / GENERAL BAIT PERMIT DURING JULY TO SEPTEMBER 2014. Which organisms do you collect on the mollusc / general bait permit? Tick the appropriate blocks.

Ghost crab

Rock crabs

Mole crab

(Sea lice)
Mussel(not in KEN)

Octopus

Mud prawn

(greenish-black, both nippers same size)
Oyster(not in KZW)

Redbait

Sand prawn

(white body, one nipper bigger than other)

Other (please specify)

Mussels and oysters may not be collected on the mollusc permit in KZN, as in the other provinces. A KZN mussel and KZN oyster permit is required to collect these animals in KZN. 
Questionnaire A.2 continued

8. For All Permit-Holders: Catch Data

Please answer the following questions about shellfish catches you made during 1 July - 30 September 2014. Add catches of species not listed at the bottom of the table.

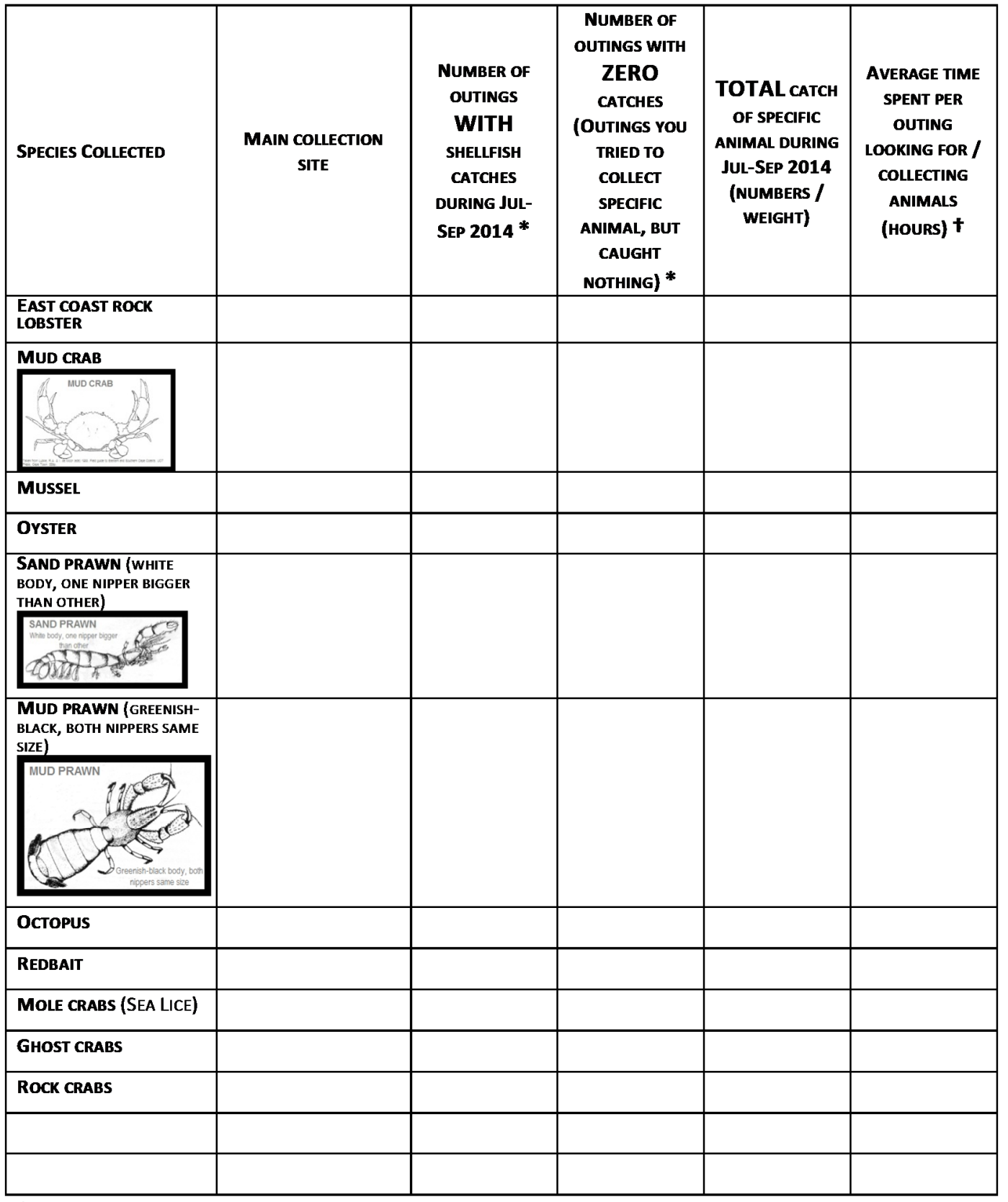

* Only include outings when an effort was made to collect a specific animal - not all fishing trips, EXCEPT if crayfish were caught on hook and line - then include all fishing trips.

$\dagger$ Only the time (hours) spend actively looking for /collecting the specific animal.

9. Please add any further comments you wish to make below: 


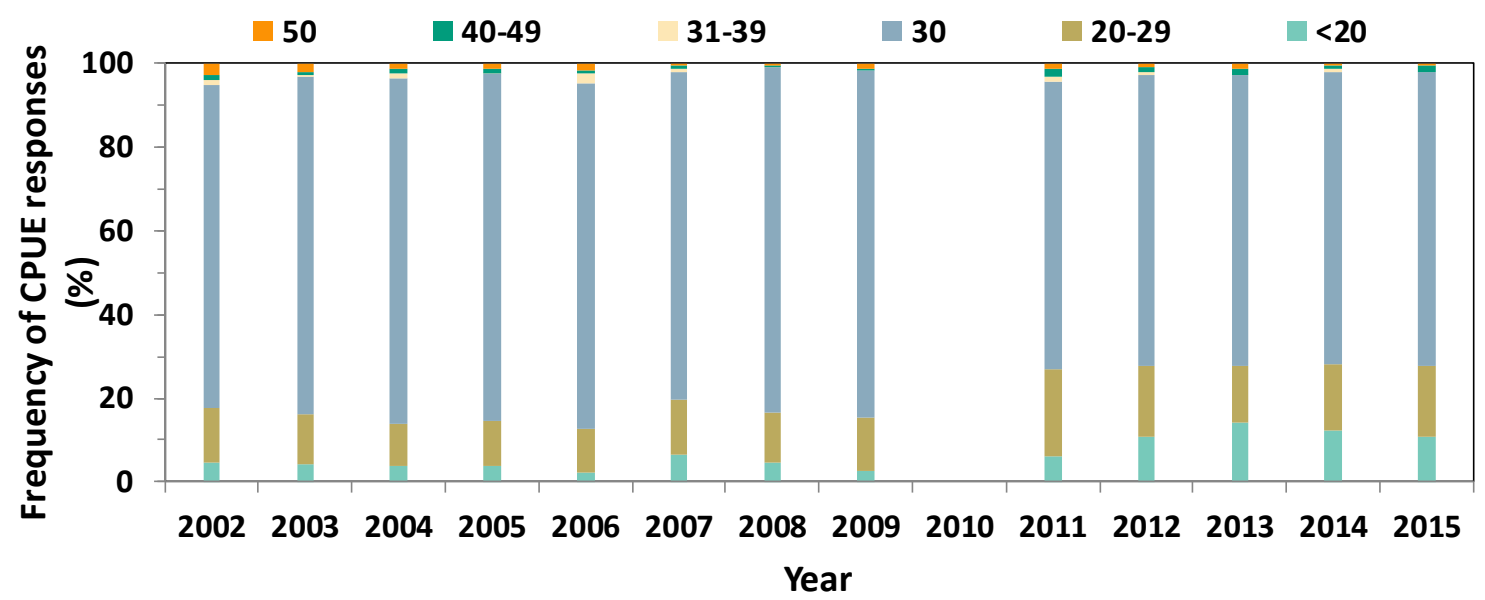

Figure A.1. The frequency of all survey respondents collecting the current daily bag limit (30 mussels/ outing), less than the bag limit (<20; 20-29 mussels), more than the bag limit (31-39; 40-49 mussels) or the old bag limit (50 mussels/ outing) of mussels. 